\title{
Expected satiation after repeated consumption of low- or high-energy-dense soup
}

\author{
Pleunie S. Hogenkamp ${ }^{1,2}$, Jeffrey M. Brunstrom ${ }^{3}$, Annette Stafleu ${ }^{1,4}$, Monica Mars ${ }^{1,2}$ \\ and Cees de Graaf ${ }^{1,2 *}$ \\ ${ }^{1}$ Top Institute Food and Nutrition, PO Box 557, NL-6700 AN Wageningen, The Netherlands \\ ${ }^{2}$ Division of Human Nutrition, Wageningen University, PO Box 8129, NL-6700 EV Wageningen, The Netherlands \\ ${ }^{3}$ Nutrition and Behaviour Unit, School of Experimental Psychology, University of Bristol, 12a Priory Road, Bristol \\ BS8 1TU, UK \\ ${ }^{4}$ TNO, PO Box 360, NL-3700 AJ Zeist, The Netherlands \\ (Submitted 7 March 2011 - Final revision received 9 August 2011 - Accepted 30 August 2011 - First published online 29 September 2011)
}

\begin{abstract}
We investigated whether repeated consumption of a low-energy-dense (LED; 208 kJ/100 g) or high-energy-dense (HED; $645 \mathrm{~kJ} / 100 \mathrm{~g}$ ) soup modifies expectations relating to the satiating capacity of the food, and its subsequent intake. In study 1, participants consumed either a

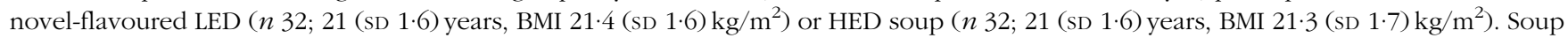
was served in a fixed amount on days 1-4 and ad libitum on day 5. 'Expected satiation' was measured on days 1, 2 and 5. Expected satiation did not change after repeated consumption of the LED or HED soup. Ad libitum intake did not differ between the LED (461 (sD 213 ) g) and HED soup (391 (SD 164) g). Only on day 1, expected satiation was higher for the HED soup than for the LED soup ( $P=0 \cdot 03$ ), suggesting a role for sensory attributes in expected satiation. In study 2 , thirty participants (21 (SD $1 \cdot 6$ ) years, BMI $21 \cdot 3(\mathrm{sD} 1 \cdot 7) \mathrm{kg} / \mathrm{m}^{2}$ ) performed a single measurement of expected satiation of the LED and HED soup, and four commercially available types of soup. Ratings on sensory attributes were associated with expected satiation. Results on expected satiation coincided with those of study 1 . Thickness and intensity of taste were independently associated with expected satiation. Expectations may initially rely on sensory attributes and previous experiences, and are not easily changed.
\end{abstract}

Key words: Food intake: Energy density: Learned satiation: Sensory attributes

The amount that people eat of a particular food is based on previous exposure to the food item ${ }^{(1)}$. There are two important factors that play a role in the amount eaten: the perception of sensory attributes of the food and the physiological effects after ingestion $^{(1,2)}$. Initially, people are not aware of the postingestive effects of a novel food and may decide on a specific volume independent of the food's energy content ${ }^{(3)}$. People will learn about the energy content by repeated exposure, and associate this with the sensory characteristics of the food. These learned associations help to estimate the satiating capacity of many foods, and to regulate food intake by adjusting portion size or energy intake in a subsequent eating occasion $^{(1,4-6)}$.

Studies on energy intake compensation in adults, however, have shown inconsistent results. Some studies have reported intake compensation in response to different energy levels provided by test foods $s^{(1,4-6)}$, while others do $\operatorname{not}^{(7-10)}$.
These inconsistent results have been explained by several factors $^{(6,11)}$. A potential explanation for the lack of compensation is that a specific amount eaten may reflect lifelong habitual intake ${ }^{(12)}$, making new learning relatively difficult. Also, humans tend to clean their plate ${ }^{(13)}$, reducing the occurrence of within-meal intake compensation.

A lack of response may also indicate that better control over the underlying factors (e.g. an adequate number of exposures or differences in energy loads to ensure effects) is needed to increase understanding of the mechanism of energy intake adjustments, and give further insight into the determinants of meal size.

The satiating efficiency per unit energy is one of the determinants that may affect actual intake ${ }^{(14)}$, and, indeed, expectations about the satiating effects of a food differ markedly across a broad range of food items ${ }^{(15)}$. Changes in expected satiation are thought to be required for an adjustment in

Abbreviations: HED, high-energy-dense; LED, low-energy-dense; VAS, visual analogue scale.

*Corresponding author: Professor C. de Graaf, fax +31 317483 342, email kees.degraaf@wur.nl 
meal size, and these expectations can be modified by learning about the food's satiating capacity by repeated consumption. Results of a previous study showed that participants changed expected satiation after one exposure to a novel test food of which energy density was covertly manipulated (either low or high), but this was not reflected in subsequent intake ${ }^{(16)}$. Changes in expected satiation were only small, and the single exposure may not have been sufficient to allow for profound learning. Repeated exposure, on the other hand, might increase the demonstrated changes in expected satiation, and consequently results in behavioural changes in intake ${ }^{(16)}$. In addition, familiarity tends to increase with repeated exposure, and it has been suggested that familiarity with a food influences its expected satiation ${ }^{(17)}$.

To test the hypothesis that expected satiation will change consistently after repeated consumption, we conducted a conditioning experiment (study 1) in which participants repeatedly consumed a fixed portion of either a low-energy-dense (LED) or a high-energy-dense (HED) soup. We anticipated that learning would be demonstrated by a conditiondependent shift in expected satiation on day 5 relative to baseline. To explore the extent to which expected satiation was associated with actual intake, we offered the soup ad libitum on day 5.

We observed a difference in expected satiation between the energy conditions at baseline in study 1 that suggested a role for sensory attributes in expected satiation. In a second study (study 2), we investigated whether participants were able to discriminate between the expected satiation of different types of soup. We measured expected satiation of the LED and HED soup from study 1 and of four commercially available types of soup. Subsequently, expected satiation was linked to the product's sensory characteristics.

Study 1. Expected satiation of a low- or high-energy-dense soup over repeated consumption

\section{Methods}

Participants. Healthy, normal-weight young adults (range 18-35 years) were recruited from Wageningen and the surrounding areas. Exclusion criteria were restrained eating (scores: males $\geq 2 \cdot 25$, females $\geq 2 \cdot 80$ based on the Dutch Eating Behaviour Questionnaire ${ }^{(18)}$ ), being a vegetarian, a change in body weight of $>5 \mathrm{~kg}$ during the last 2 months, an energy-restricted diet during the last 2 months, having difficulties with swallowing/eating, lack of appetite and suffering from gastrointestinal or endocrine disorders. Participants were pair-matched for BMI, restraint score and age, and randomly assigned to one of two conditions, consuming either a LED or a HED soup. In total, sixty-four participants completed the conditioning experiment (see Table 1 for characteristics).

Participants were unaware of the exact aim of the study, and were told that we investigated the effect of frequent consumption of 'soup as a main course' on their daily dietary pattern. The present study was conducted according to the guidelines laid down in the Declaration of Helsinki and all procedures involving human subjects were approved by the Medical Ethical Committee of the Wageningen University (NL28577.081.09). The trial has been registered with the Dutch Trial Register (Nederlands Trialregister (NTR); registration no. NTR 1988). Written informed consent was obtained from all subjects

Design. In a between-subject design, participants were offered either a LED or a HED soup for lunch on five consecutive days (Monday to Friday). On days 1-4, the soup was served in a fixed volume; on day 5 , the soup was served ad libitum and intake was assessed. Expected satiation was measured on days 1, 2 and 5, to get further insight into the effect of repeated consumption (measure day 5) on expectations, compared with a single exposure (measure day 2). Preceding the conditioning experiment, the participants were trained in the procedures, which are explained below.

Test food. The following two versions of a novel flavoured and coloured soup were developed for the present study: a LED $(208 \mathrm{~kJ} / 100 \mathrm{~g})$ and a HED $(645 \mathrm{~kJ} / 100 \mathrm{~g})$ version, similar in appearance. A homogeneous soup was prepared on the basis of a white sauce ('roux'), which consisted of sunflower oil $(30 \mathrm{~g})$, fine wheat flour $(40 \mathrm{~g})$, fine vegetable broth powder (10 g 'Knorr'; Unilever Nederland B.V., Rotterdam, The Netherlands), salt (2 g), a pesto-flavoured herbal mix (6g 'Green Pesto Dipper'; Duyvis Smiths Food Group B.V., Utrecht, The Netherlands) and a green food-colouring agent

Table 1. Characteristics of the participants in study 1, in both low-energy-dense (LED) or highenergy-dense (HED) soup conditions ${ }^{*}$, and in study $2 \dagger$

(Mean values and standard deviations)

\begin{tabular}{|c|c|c|c|c|c|c|}
\hline & \multicolumn{4}{|c|}{ Study 1} & & \\
\hline & \multicolumn{2}{|c|}{ LED ( $n$ 32) } & \multicolumn{2}{|c|}{ HED ( $n$ 32) } & \multicolumn{2}{|c|}{ Study 2 ( $n$ 30) } \\
\hline & Mean & SD & Mean & SD & Mean & SD \\
\hline Male & \multicolumn{2}{|c|}{12} & \multicolumn{2}{|c|}{11} & \multicolumn{2}{|c|}{10} \\
\hline Female & \multicolumn{2}{|c|}{20} & \multicolumn{2}{|c|}{21} & \multicolumn{2}{|c|}{20} \\
\hline BMI $\left(\mathrm{kg} / \mathrm{m}^{2}\right)$ & 21.4 & 1.6 & 21.3 & 1.7 & $22 \cdot 7$ & $2 \cdot 1$ \\
\hline Restraint score $\left(\mathrm{DEBQ}^{(18)}\right) \ddagger$ & 1.9 & 0.6 & $2 \cdot 0$ & 0.5 & $2 \cdot 6$ & 0.8 \\
\hline Age (years) & 21 & 1.6 & 21 & 1.6 & 27 & $5 \cdot 8$ \\
\hline
\end{tabular}

DEBQ, Dutch Eating Behaviour Questionnaire.

${ }^{*}$ Participants were matched for BMI, restraint score and age.

† Different participants were tested in study 1 and study 2 .

‡Restraint scale: 1 , not at all; 5 , very high. 
( $5 \mathrm{ml} / 1000 \mathrm{~g}$ for the LED soup, $3.7 \mathrm{ml} / 1000 \mathrm{~g}$ for the HED soup; Jo-La, Chan's B.V., Alphen a/d Rijn, The Netherlands) for every $1000 \mathrm{~g}$ soup. In addition, lecithin powder ( $5 \mathrm{~g}$; Zonnatura, Zonnatura B.V., Utrecht) was used as an emulsifier.

The energy density of the HED soup was manipulated by an increased quantity of sunflower oil $(+70 \mathrm{~g})$, and by the addition of maltodextrin (82 g Fantomalt; Nutricia Nederland B.V., Zoetermeer, The Netherlands) and protein powder (15 g Peptan P; Rousselot S.A.S., Son, The Netherlands). For every $1000 \mathrm{~g}$ soup, $902 \mathrm{~g}$ water was added to the LED soup and $735 \mathrm{~g}$ water to the HED soup.

Macronutrient content was determined by chemical analysis of samples taken from a homogeneous mixture of samples that were collected every testing day. The proportion of energy provided by the different macronutrients was similar for the LED and HED soup (Table 2).

The soup was served in a preheated bowl at $65^{\circ} \mathrm{C}$. During the conditioning period (days 1-4), soup was served in a fixed volume of $300 \mathrm{~g}$ for women and $400 \mathrm{~g}$ for men. On day 5 , all participants were served $1000 \mathrm{~g}$ of soup. When the weight of the soup fell below $100 \mathrm{~g}$, a researcher was alerted by the computer and the bowl was refilled. This happened only once and in the LED condition.

Measurement of expected satiation. In both studies, expected satiation was measured using a 'method of adjustment' (based on Brunstrom et al. ${ }^{(15)}$ ). This method has been shown to be an effective and sensitive measure of expectations $^{(15,16)}$. During the measurements, the soup was physically present and assessed against seven commonly consumed 'comparison foods'. Pictures of each comparison food were shown on a computer screen. The order of appearance of these foods was randomised across participants, and the trial started with a different and randomly selected amount for each comparison food. After a single spoonful of soup, participants were asked to indicate the amount of food on the picture that would be equally as satiating as the bowl of soup in front of you immediately after consumption'.
The amount could easily be adjusted using the arrow keys on the keyboard. The pictures were loaded with sufficient speed in a way that continuous use of the arrow keys gave the impression that the change in the amount of food was 'animated'. The amount that could be displayed ranged from 347 to $3138 \mathrm{~kJ}$ ( 83 to $750 \mathrm{kcal}$ ). A total of fifty-one pictures were used to display these amounts. Picture number 25 displayed a $1046 \mathrm{~kJ}(250 \mathrm{kcal})$ portion. Picture number 0 displayed 0.3 times and picture number 50 displayed 3 times this amount, i.e. the amount increased 1.05 times with each picture in the series. All comparison foods used were meal items, i.e. foods commonly consumed to satiation, which were familiar to our participants (indicated on a questionnaire at intake). We assumed this would enable the participants to indicate the expected satiation precisely based on previous exposure to the comparison foods. The comparison foods included small potatoes (boiled; $314 \mathrm{~kJ} / 100 \mathrm{~g}$ ), rice curry ('chicken tikka masala'; $460 \mathrm{~kJ} / 100 \mathrm{~g}$ ), penne and tomato sauce $(502 \mathrm{~kJ} / 100 \mathrm{~g})$, spaghetti Bolognese (590 kJ/100 g), oven fries $(1100 \mathrm{~kJ} / 100 \mathrm{~g})$, cheese and tomato pizza $(1293 \mathrm{~kJ} / 100 \mathrm{~g})$, and baguettes with garlic and herb butter (1423kJ/100 g).

Procedures. Participants were asked to refrain from eating from 23.00 hours the day before each test day and to consume a self-selected, identical breakfast on each test day. Participants consumed their standardised breakfast at least $3 \mathrm{~h}$ before the start of the lunch. Consumption of non-energy beverages was permitted up to $1 \mathrm{~h}$ before the test session. After each test session, the participants were instructed not to eat anything for at least $2 \mathrm{~h}$. Food diaries were used to increase compliance to the eating and drinking restrictions, and reported consumption confirmed adherence to the procedures.

Participants were tested in isolated sensory cabins at the same time each test day, either 11.30 hours ( $n$ 20), 12.30 hours ( $n 29$ ) or 13.30 hours ( $n 15$ ). Soup was prepared freshly for every lunch session. On arrival, participants rated their appetite sensations (hunger, fullness, desire to eat and prospective consumption). Ratings were performed on a

Table 2. Energy, macronutrient composition and energy percentage of macronutrients of the low-energy-dense (LED) and high-energy-dense (HED) soup of study 1 and study 2 and commercially available types of soup of study 2

\begin{tabular}{|c|c|c|c|c|c|c|}
\hline & \multicolumn{2}{|c|}{ Study 1 and study 2} & \multicolumn{4}{|c|}{ Study 2} \\
\hline & LED* $^{*}$ & $\mathrm{HED}^{*}$ & Chicken† & Mushroom† & Tomato† & Pea† \\
\hline \multicolumn{7}{|l|}{ Energy } \\
\hline $\mathrm{kJ}$ & 208 & 645 & 93 & 145 & 201 & 351 \\
\hline kcal & 50 & 154 & 20 & 34 & 48 & 83 \\
\hline \multicolumn{7}{|c|}{ Carbohydrates } \\
\hline $\mathrm{g}$ & 3.6 & $11 \cdot 3$ & 2 & 3.9 & $6 \cdot 8$ & $9 \cdot 2$ \\
\hline$\%$ energy & 30 & 29 & 40 & 46 & 57 & 44 \\
\hline \multicolumn{7}{|l|}{ Protein } \\
\hline$g$ & 0.7 & $2 \cdot 3$ & 2 & 1 & 1.2 & 3.7 \\
\hline$\%$ energy & 6 & 6 & 40 & 11 & 10 & 18 \\
\hline \multicolumn{7}{|l|}{ Fat } \\
\hline g & $3 \cdot 8$ & $11 \cdot 2$ & 0.6 & 1.4 & 1.6 & 3.7 \\
\hline \% energy & 64 & 65 & 27 & 39 & 31 & 40 \\
\hline Fibre (g) & 0.05 & 0.31 & 0.2 & 0.1 & 0.4 & $4 \cdot 2$ \\
\hline
\end{tabular}

* Shown per $100 \mathrm{~g}$ soup. Values determined by chemical analyses of samples taken from a homogeneous mixture of samples collected every testing day.

†Shown per $100 \mathrm{~g}$ soup. Values based on nutritional information provided by the producer (per $100 \mathrm{ml}$ soup). 
100-unit visual analogue scale (VAS), anchored 'not at all' to 'extremely' for hunger, fullness and desire to eat, and 'nothing at all' to 'very much' for prospective consumption. Participants then received a bowl of soup, consumed a single spoonful, and rated the pleasantness, familiarity and sensory attributes of the soup, all on a 100-unit VAS. Sensory attributes included sweetness, saltiness, creaminess, thickness, intensity of taste, intensity of herbs and intensity of aftertaste. On days 1, 2 and 5, expected satiation was measured immediately after these ratings. On days 1 and 2, participants were then instructed to consume the fixed load of soup. On day 5, soup was offered ad libitum and participants were instructed 'to eat as much as you like until you feel comfortably satiated'. The bowls were weighed before and after consumption to obtain soup intake. On days 3 and 4, participants consumed the fixed load of soup immediately after rating the sensory attributes of the soup. After soup consumption, participants again rated its pleasantness, familiarity and sensory attributes, and their appetite sensations on a 100-unit VAS.

Data analysis. Continuous variables are presented as means and standard deviations, and categorical variables are presented as frequencies. For each participant, the selected amounts of all seven comparison foods (in $\mathrm{kJ}$ ) were averaged. This average represents the expected satiation of the soup, i.e. the amount (in $\mathrm{kJ}$ ) that is expected to be equally as filling as the bowl of soup.

Expected satiation scores were log-transformed before being entered into our analysis. For reasons of clarity, we converted the data into corresponding $\mathrm{kJ}$ when mean values are presented.

Effects of repeated consumption, energy condition and their interaction effect on expected satiation, appetite sensations and sensory attributes were tested using ANOVA (mixedmodel procedure), and Tukey's post hoc tests were used to test for differences between the energy conditions and test days. Delta scores refer to the decrease in ratings on hunger, desire to eat and prospective consumption, and the increase in fullness ratings after consumption of the soup.

We used an independent-samples $t$ test to compare differences in ad libitum intake (both volume and energy) of the LED and HED soup.

Data were analysed using SAS (version 9.1; SAS Institute, Inc., Cary, NC, USA). Results at a $P$ value of $<0.05$ were considered significantly different.

\section{Results}

Expected satiation. Expected satiation did not change over repeated consumption $(F(1,126)=0 \cdot 01 ; P=0 \cdot 89)$, not for the LED $\operatorname{soup}(F(1,63)=0.96 ; P=0.33)$ nor for the HED soup $(F(1,63)=2 \cdot 11 ; P=0 \cdot 15)$. We observed a main effect of energy condition on expected satiation $(F(1,62)=5 \cdot 07 ; \quad P=0.03)$. Post hoc tests revealed that the expected satiation of the HED soup was higher than the LED soup on day $1(t=-2 \cdot 16$; $P=0.03)$, and did not differ between the LED and HED soup on the subsequent test days (Fig. 1). The interaction between energy condition and repeated consumption was not statistically significant $(F(1,62)=2 \cdot 80 ; P=0 \cdot 10)$.

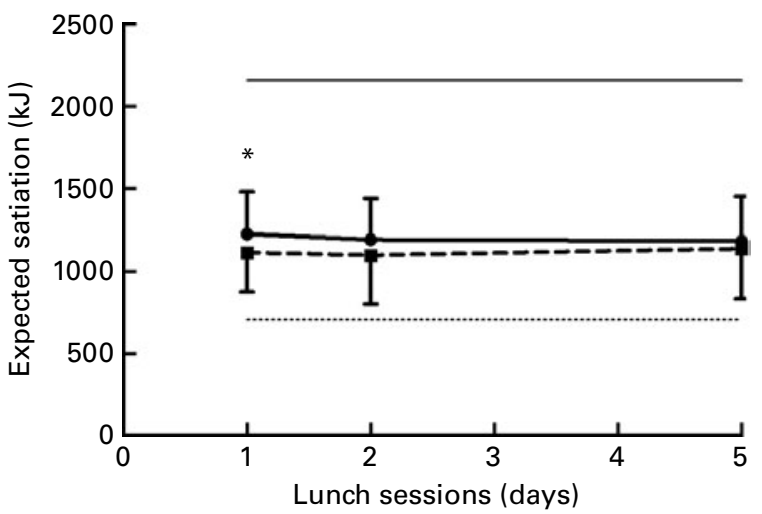

Fig. 1. Expected satiation (kJ) of the low-energy-dense (LED; -----) and high-energy-dense (HED; - ) soup over repeated consumption in study 1. Values are means, with standard deviations represented by vertical bars. The actual energy load ( $\mathrm{KJ}$ ) as served in the LED (thin dotted line) and HED $(-)$ condition is indicated as a weighted average of sex (women were served $300 \mathrm{~g}$, men $400 \mathrm{~g}$ ). *Expected satiation of the HED soup was higher than that of the LED soup on day $1(P=0.03)$.

Ad libitum intake. The volume of soup consumed when offered ad libitum was not significantly different between the LED (461 (SD 213) g) and the HED soup (391 (SD 164) g; $P=0 \cdot 14)$. Energy intake, however, was higher in the HED condition (2452 (SD 1029) kJ) than in the LED condition (925 (SD 427) $\mathrm{kJ} ; t=-9 \cdot 23 ; P<0 \cdot 0001)$.

Appetite sensations. No differences in any of the sensations of appetite before or after consumption, nor in the delta scores were found between the LED and HED soup (all $P>0 \cdot 05$ ). Delta scores were significantly greater after ad libitum intake compared with the consumption of the fixed loads of soup (all $P<0 \cdot 01$ ), except for fullness on day 1 compared with fullness after ad libitum intake (data not shown).

Sensory attributes. None of the ratings on the sensory attributes changed over repeated consumption, but we observed a main effect of energy condition on pleasantness $(F(1,254)=6.59 ; \quad P=0.01), \quad$ creaminess $\quad(F(1,254)=16 \cdot 96$; $P<0 \cdot 0001)$ and thickness $(F(1,254)=9 \cdot 22 ; P=0 \cdot 003)$. Ratings on these attributes after one spoonful differed between energy conditions (all $P<0 \cdot 01$ ), with the HED soup evaluated to be more pleasant, thicker and creamier than the LED soup on day 1 (Table 3). Differences in creaminess and thickness soup persisted over all test days $(P<0 \cdot 001)$. Pleasantness ratings after one spoonful were not different between the LED and HED soup on days 2-5, or after consumption of a complete bowl of soup on any of the test days. Familiarity ratings increased over repeated consumption (51 (SD 20) units VAS on day 1 to 69 (SD 25) units VAS on day 5; $F(1,248)=56 \cdot 08$; $P<0.0001$ ), but were not different between the LED and HED soup $(F(1,248)=0 \cdot 16 ; P=0 \cdot 69)$.

\section{Interim discussion}

The objective of the present study was to investigate whether expected satiation changes in response to repeated consumption of a LED or HED soup, indicating that learning modifies expectations. The present results show that expected satiation remained unchanged over the 5 -d period. 
At baseline, expected satiation of the HED soup was higher than that of the LED soup. This difference was relatively small compared with the actual difference in energy content, and we observed no differences in expected satiation after repeated consumption. To explore the direct effect of expected satiation on food intake, we offered the soup ad libitum on day 5. The ad libitum intake was equal in the LED and HED condition, corresponding with the lack of differences in expected satiation. Although we did not measure ad libitum intake at baseline, the similar volume intake after repeated consumption implies that participants did not have reason to adjust their meal size in response to the considerable differences in energy density of the soup in the two conditions. Participants may have consumed a 'regular amount' of soup, with the volume consumed as the primary determinant of intake regulation ${ }^{(3,19)}$. As a consequence, the energy intake in the high-energy condition (2452 kJ) was more than 2-fold the energy intake in the lowenergy condition $(925 \mathrm{~kJ})$. Since we were especially interested in the effects of learning on meal size, we did not collect information on feelings of satiety or food intake during the remainder of the day. Adequate intake compensation in response to the differences in energy density beyond the meal provided, however, seems unlikely ${ }^{(14,20,21)}$.

Participants consumed the soup in a fasted state and abstained from eating $2 \mathrm{~h}$ after the test session, to ensure awareness of the satiating effects. Expected satiation, however, did not change after repeated consumption of the LED or HED soup. Several reasons can be considered for the apparent absence of learning about the satiating capacity of this test soup.

When the soup was offered ad libitum at day 5, the volume consumed was higher than the fixed load of soup provided on days $1-4$, resulting in greater changes in sensations of appetite. This implies that participants may not have been comfortably satiated during the conditioning period. It has been suggested that learning is most effective when a food is eaten to fullness, and causes a persistent change in expectations of the specific food ${ }^{(22)}$. The fixed amount we served was based on the average intake at lunch of Dutch young adults (male/female: $2540 \mathrm{~kJ} / 1766 \mathrm{~kJ})^{(23)}$, and on previous results on ad libitum intake of a homogeneous soup with similar energy density as our LED soup (intake males: $423 \mathrm{~g}$, females: $340 \mathrm{~g})^{(24)}$. The fixed loads in the present study, however, may not have been adequate to evoke significant differences in post-ingestive effects that facilitate learning.

Additionally, the study aim communicated to the participants may have modified their expectations. 'Frequent consumption of soup as a main course' implies that the soup will provide a substantial meal, which will be satiating upon finishing. Previous studies investigating hedonic expectations have shown that evaluation after consumption is generally adjusted towards expectations ${ }^{(25,26)}$, especially after negative confirmation $^{(27)}$. Only when foods taste much better than expected $^{(25)}$ or when there is a large contrast between expectation and evaluation ${ }^{(28)}$, future expectations will be adjusted. This adjustment of evaluation towards prior expectations may also affect changes in expectations of the satiating capacity of 
a food ${ }^{(25)}$. Despite the large difference in energy density of the provided soups, the contrast between the 'expected substantial meal' and actual post-ingestive effects may not have been sufficient to change expected satiation.

It can be argued that the 'pesto'-soup was novel within the category of soup products, but not highly novel in itself. Increases in familiarity ratings were only small, and possibly not sufficient to affect expectations. Expectations could then have been based on soup in general and reflect beliefs on an 'prototypical' item of the specific food category ${ }^{(29)}$. Based on repeated consumption over lifetime, people have learned that soup in general is a very satiating product ${ }^{(30,31)}$. This may have limited the learning of new flavour-nutrient associations, thereby inhibiting a possible change in expected satiation. Moreover, $4 \mathrm{~d}$ of repeated consumption may have been insufficient to change beliefs about a familiar product ${ }^{(32,33)}$. Results in Fig. 1 suggest that participants adjusted their expected satiation after the first exposure already, although the adjustments were small and not statistically significant. Using a more novel food may have resulted in profound changes in expected satiation after one exposure ${ }^{(16)}$.

Overall, the results indicate that cognitive factors related to the food's satiating capacity are very hard to change. The apparent absence of adequate learning may facilitate overconsumption, since conditions that are required for learning to occur may be suboptimal in the complex dietary environment in our daily life.

Since expected satiation may play a role in decisions on meal size, understanding its underlying factors can expand our current insight into the regulation of food intake. To further investigate the determinants of expected satiation, we refer to the difference in expected satiation between the two test soups at baseline. This difference indicates that participants discriminated the two soups based on the first spoonful, and implies that expectations were not exclusively based on volume of the soup. Other factors, such as differences in sensory characteristics (Table 3), may also play a role.

We examined this difference in expected satiation in more detail, and assessed the extent to which participants were able to discriminate between different food items from one product category, i.e. to discriminate between different types of soup. We performed a single measurement of expected satiation of the LED and HED soup from study 1, and of four commercially available types of soup (study 2). Participants evaluated all six types of soup, and judged perceived intensity of several sensory attributes that were subsequently associated with expected satiation.

\section{Study 2. Expected satiation of six types of soup}

\section{Methods}

Participants. A total of thirty adults participated in the present study (see Table 1 for characteristics). Recruitment procedures were as in study 1. Different participants were tested in study 1 and study 2 .

Design. In a within-subject design, participants conducted a single measurement of expected satiation of six types of soup: the LED and HED soup from study 1, and four commercially available types of soup that were assumed to be consumed regularly. Soup was presented in a fixed volume of $300 \mathrm{~g}$ for women and $400 \mathrm{~g}$ for men, and participants tasted a single spoonful from each type of soup. Ratings on perceived intensity of sensory attributes were associated with expected satiation.

Test food. We measured expected satiation of the LED and HED soup from study 1 , and of four commercially available types of soup: chicken ('Unox Stevige-soep-in-blik'; Unilever Nederland B.V.), mushroom, tomato and pea (all 'Unox Soep-in-zak'; Unilever Nederland B.V.). The chicken soup was a clear soup with pieces of chicken (5.5\%), carrot and noodles; the mushroom soup was a cream soup (based on skimmed milk powder) with mushrooms (6.5\%); the tomato soup contained tomatoes ( $82 \%)$, basil and oregano; the pea soup contained peas (21\%), smoked sausage (5\%), and small pieces of potato, carrot, bacon and onion (all $<4 \%$ ). Energy density and macronutrient composition of all types of soup are reported in Table 2.

Procedures. Participants had a single test session at 11.00 hours ( $n$ 7), 12.00 hours ( $n$ 12), 13.00 hours $(n 9)$ or 14.00 hours ( $n$ 2). Breakfast was consumed at least $3 \mathrm{~h}$ before the start of the session. Participants rated their appetite sensations on a 100-unit VAS on arrival, and ratings on hunger, fullness, desire to eat and prospective consumption confirmed adherence to the breakfast instructions. We demonstrated the measurement of expected satiation, and presented the first bowl of soup. Participants tasted a single spoonful, rated pleasantness, familiarity and sensory attributes (sweetness, saltiness, creaminess, thickness, intensity of taste, intensity of herbs and intensity of aftertaste), and completed the measurement of expected satiation. Participants were then instructed to return the bowl of soup and to neutralise their taste by eating plain crackers and drinking water. This procedure was repeated for all the types of soup. The order of presentation was randomised within participants. The measurement of expected satiation was conducted as in study 1 .

Data analysis. As in study 1 , the selected amounts of all seven comparison foods (in $\mathrm{kJ}$ ) were averaged for each participant to calculate the expected satiation of each soup. Analyses were conducted with log-transformed data, and converted into corresponding $\mathrm{kJ}$ when mean values are presented.

The effect of the type of soup on expected satiation was tested using ANOVA, and Tukey's post hoc test was used to test for differences between the types of soup. We assessed associations between sensory attributes and expected satiation using Pearson's correlation coefficients $(r)$ and their associated 95\% CI. Multivariate stepwise linear regression analysis with backward elimination was used to test independence of these associations. The differences in expected satiation between study 1 and study 2 were tested with a two-sample $t$ test.

Data were analysed using SAS (version 9.1; SAS Institute, Inc.). Results at a $P$ value of $<0.05$ were considered significantly different. 


\section{Results}

Expected satiation. Fig. 2 shows the expected satiation for each of the six types of soup, as well as their actual energy content as served. Except for the HED soup, all types were expected to be more filling than the comparison foods, $\mathrm{kJ}$ for kJ. Expected satiation differed significantly across the soups $(F(5,145)=14 \cdot 87 ; P<0 \cdot 0001)$.

Post hoc tests showed that expected satiation of the chicken soup was lower than that of all other types of soup; expected satiation of the pea soup was higher than that of all other types of soup (all $P<0.0001$ ). The difference between expected satiation of the LED and HED soup was borderline significant $(t=2.85 ; P=0.06)$. Expected satiation did not differ from study 1 for the LED soup (study 1: 1113 (SD 238) kJ $v$. study 2: 1099 (sD 309) kJ; $t=0 \cdot 13, P=0 \cdot 90$ ) or the HED soup (study 1: 1224 (SD 254) kJ $v$. study 2: 1289 (SD 449) kJ; $t=-0 \cdot 19, P=0 \cdot 85)$. We observed no differences in expected satiation between the tomato soup, the mushroom soup and the LED soup, or between the tomato soup, the mushroom soup and the HED soup.

Sensory attributes. Thickness, creaminess, intensity of taste, intensity of aftertaste and intensity of herbs were positively correlated with expected satiation of the different types of soup (Table 3).

Regression analysis showed that only thickness and intensity of taste were independently associated with expected satiation. These two sensory attributes accounted for $40 \%$ of the variability in expected satiation $\left(R^{2} 0 \cdot 40\right)$

\section{Discussion}

In this second study, we conducted a single measurement of expected satiation of the LED and HED soup and four commercially available types of soup in a within-subject design, and with different participants tested. The present findings coincide with those from study 1 . They show that the used method of adjustment is a reproducible measure, and a precise means to assess expectations. Moreover, the results

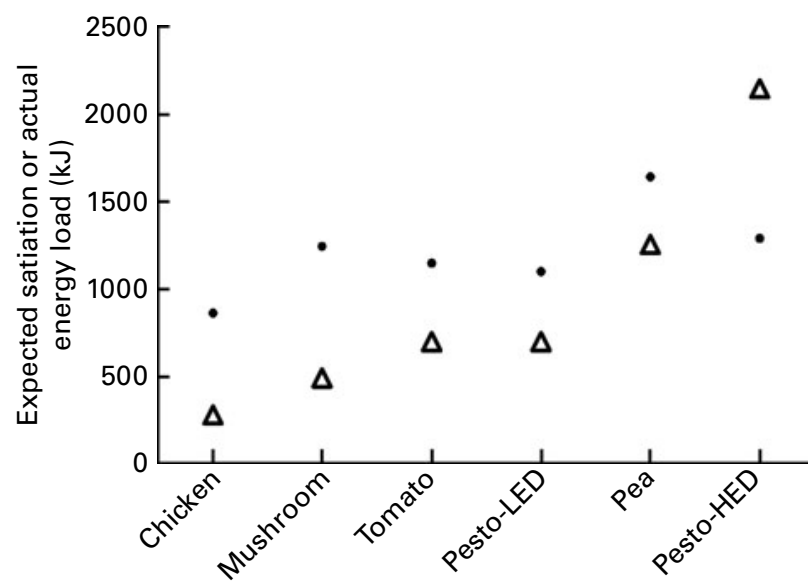

Fig. 2. Expected satiation ( $\mathrm{kJ} ; \bullet$ ) and actual energy load (kJ; $\Delta$ ) of six types of soup as served in study 2 (weighted average of sex; women were served $300 \mathrm{~g}$, men $400 \mathrm{~g}$ ). LED, low-energy-dense soup from study 1 ; HED, highenergy-dense soup from study 1. indicate that people discriminated the test soups and estimated the order of the satiating capacity of different types of soup reasonably well.

Expected satiation is assumed to guide decisions on meal size, with selection of different portion sizes of food items differing in expected satiation. A previous study, however, reported similar intake of the two test foods despite differential changes in expected satiation ${ }^{(16)}$. One explanation for the similar intake is that prolonged exposure will be required before behavioural changes may be observed. Another explanation is that the type of test foods, i.e. sorbets, may have limited the observation of intake compensation: one may not be used to eat dessert-specific products until satiation, since these foods are in general consumed in a fixed amount after dinner. Meals consumed in daily life, however, often consist of several food items, and intake compensation may be demonstrated more easily by adjusted intake of food items that are used to be eaten until satiation, e.g. familiar staple foods. The satiating capacity of these foods may be well known and may therefore facilitate decisions on an adequate portion size. The effect of differences in expected satiation on actual intake warrants further investigation.

The differences in expected satiation in study 2 suggest that the absence of changes in expected satiation in study 1 is not due to insensitivity to differences between the soups, and that equal volumes of the different soups do not result in equal expectations of satiating capacity per se. Instead, the differences suggest that we are sensitive to subtle characteristics of soup, but prior experiences with these characteristics, familiarity with the test food's product category, and an insufficient contrast between expectations and evaluation may have limited relearning in study 1 . Expectations as reported in study 2 may reflect the actual satiation that has been experienced throughout life when consuming that specific soup. Expectations may also reflect the evaluation of the sensory characteristics in general, with perceived thickness as an important determinant of expected satiation: more solid foods have been experienced to be more satiating than liquid foods ${ }^{(34-36)}$. In either way, this suggests that expectations relating to the satiating capacity of a food are based on learning throughout lifetime, and are not easily changed. This may explain the absence of energy adjustments in other flavour-nutrient learning studies.

It also gives further insight into the particular conditions that are required for learning to occur. As suggested, a prolonged exposure period may be essential for a behavioural change, but it will be hard to define the extent to which the conditioning period must be extended to show evidence for learning or relearning. Also, serving highly novel foods might enable learning to occur: expected satiation of novel foods will not yet be strongly based on previous experiences and therefore susceptible to change. More important, learning may be promoted by a large contrast between the pre-existing beliefs and the post-ingestive evaluation of a specific food. This can be realised by, for example, large differences in energy density or texture between the versions of the test food, which do not comply with expectations relating to the food's satiating capacity. 


\section{Conclusion}

Adults did not adjust their expected satiation in response to repeated consumption of the LED or HED soup in study 1. The apparent absence of learning and consequent intake adjustments may facilitate overconsumption. Energy learning may require a large contrast between expectations and postconsumption evaluation to occur. Results of study 2 indicate that expected satiation did not exclusively depend on the volume served, but that participants were able to discriminate between the soups with different sensory attributes and energy content. Expectations may initially rely on sensory attributes and previous experiences.

Expected satiation is assumed to be an important determinant in decision on portion size. It will be interesting to further investigate its role in actual food intake, and to get more insight into the possibility to change expectations regarding a food's satiating capacity and in the food characteristics that may play a role in this.

\section{Acknowledgements}

We thank all participants and research assistants (Natasja Hück, Kathryn Brown, Nicole Konijn, Sandra Bukman); Els Siebelink, Karin Borgonjen, Pauline Claessen and Corine Perenboom for dietary advice; and Tineke van Roekel for the chemical analyses. This study was supported by the Top Institute Food and Nutrition. The authors' responsibilities were as follows: P. S. H. and C. d. G. designed the study; P. S. H. conducted the research and wrote the manuscript; P. S. H., J. M. B. and M. M. analysed the data; all authors interpreted the data and critically revised the manuscript. None of the authors had a personal or financial conflict of interest.

\section{References}

1. Booth DA, Mather P \& Fuller J (1982) Starch content of ordinary foods associatively conditions human appetite and satiation, indexed by intake and eating pleasantness of starch-paired flavours. Appetite 3, 163-184.

2. Shepherd R (1988) Sensory influences on salt, sugar and fat intake. Nutr Res Rev 1, 125-144.

3. Bell EA, Roe LS \& Rolls BJ (2003) Sensory-specific satiety is affected more by volume than by energy content of a liquid food. Physiol Behav 78, 593-600.

4. Yeomans MR, Weinberg L \& James S (2005) Effects of palatability and learned satiety on energy density influences on breakfast intake in humans. Physiol Behav 86, 487-499.

5. Louis-Sylvestre J, Tournier A, Verger P, et al. (1989) Learned caloric adjustment of human intake. Appetite 12, 95-103.

6. Mars M, Hogenkamp PS, Gosses AM, et al. (2009) Effect of viscosity on learned satiation. Physiol Behav 98, 60-66.

7. Specter SE, Bellisle F, Hémery-Véron S, et al. (1998) Reducing ice cream energy density does not condition decreased acceptance or engender compensation following repeated exposure. Eur J Clin Nutr 52, 703-710.

8. Zandstra EH, Stubenitsky K, De Graaf C, et al. (2002) Effects of learned flavour cues on short-term regulation of food intake in a realistic setting. Physiol Behav 75, 83-90.

9. Raben A, Vasilaras TH, Moller AC, et al. (2002) Sucrose compared with artificial sweeteners: different effects on ad libitum food intake and body weight after 10 wk of supplementation in overweight subjects. Am J Clin Nutr 76, $721-729$

10. Hogenkamp PS, Mars M, Stafleu A, et al. (2010) Intake during repeated exposure to low- and high-energy-dense yogurts by different means of consumption. Am J Clin Nutr 91, 841-847.

11. Yeomans M (2010) Understanding individual differences in acquired flavour liking in humans. Chem Percept 3, 34-41.

12. Brunstrom JM \& Mitchell GL (2007) Flavor-nutrient learning in restrained and unrestrained eaters. Physiol Behav 90, 133-141.

13. Fay SH, Ferriday D, Hinton EC, et al. (2011) What determines real-world meal size? Evidence for pre-meal planning. Appetite 56, 284-289.

14. Kissileff HR, Gruss LP, Thornton J, et al. (1984) The satiating efficiency of foods. Physiol Behav 32, 319-332.

15. Brunstrom JM, Shakeshaft NG \& Scott-Samuel NE (2008) Measuring 'expected satiety' in a range of common foods using a method of constant stimuli. Appetite 51, 604-614.

16. Wilkinson LL \& Brunstrom JM (2009) Conditioning 'fullness expectations' in a novel dessert. Appetite 52, 780-783.

17. Brunstrom JM, Shakeshaft NG \& Alexander E (2010) Familiarity changes expectations about fullness. Appetite $\mathbf{5 4}$, 587-590.

18. Van Strien T (2005) Nederlandse Vragenlijst voor Eetgedrag (NVE). Handleiding (Dutch Eating Behaviour Questionnaire. Manual). Amsterdam: Boom Test Publishers.

19. Rolls BJ, Castellanos VH, Halford JC, et al. (1998) Volume of food consumed affects satiety in men. Am J Clin Nutr 67, $1170-1177$.

20. Levitsky DA, Obarzanek E, Mrdjenovic G, et al. (2005) Imprecise control of energy intake: absence of a reduction in food intake following overfeeding in young adults. Physiol Behav 84, 669-675.

21. Caputo FA \& Mattes RD (1992) Human dietary responses to covert manipulations of energy, fat, and carbohydrate in a midday meal. Am J Clin Nutr 56, 36-43.

22. Irvine MA, Brunstrom JM \& Rogers PJ (2009) Exploring expected satiety for common foods with a novel psychophysical methodology. Appetite 52, 839.

23. Hulshof K, Ocké M \& Van Rossum C, et al. (2004) Resultaten van de Voedselconsumptionpeiling 2003 (Results of the National Food Consumption Survey 2003). RIVM report 350030002. http://www.rivm.nl/bibliotheek/ rapporten/350030002.html (accessed September 2011).

24. Bolhuis DP, Lakemond CMM, de Wijk RA, et al. (2010) Effect of salt intensity on ad libitum intake of tomato soup similar in palatability and on salt preference after consumption. Chem Senses 35, 789-799.

25. Wansink B, Ittersum K \& Painter JE (2004) How diet and health labels influence taste and satiation. J Food Sci 69 S340-S346.

26. Cardello AV \& Sawyer FM (1992) Effects of disconfirmed consumer expectations on food acceptability. I Sensory Stud 7, 253-277.

27. Siret F \& Issanchou S (2000) Traditional process: influence on sensory properties and on consumers' expectation and liking Application to pate de campagne. Food Qual Prefer 11, 217-228.

28. Yeomans MR, Chambers L, Blumenthal H, et al. (2008) The role of expectancy in sensory and hedonic evaluation: the case of smoked salmon ice-cream. Food Qual Prefer 19 565-573.

29. Brunstrom JM (2007) Associative learning and the control of human dietary behavior. Appetite 49, 268-271. 
30. Mattes RD (2005) Soup and satiety. Physiol Behav 83, 739-747.

31. Rolls BJ (2009) The relationship between dietary energy density and energy intake. Physiol Behav 97, 609-615.

32. O'Sullivan HL, Alexander E, Ferriday D, et al. (2010) Effects of repeated exposure on liking for a reduced-energy-dense food. Am J Clin Nutr 91, 1584-1589.

33. Brunstrom JM (2005) Dietary learning in humans: directions for future research. Physiol Behav 85, 57-65.
34. Hulshof T, De Graaf C \& Weststrate JA (1993) The effects of preloads varying in physical state and fat content on satiety and energy intake. Appetite 21, 273-286.

35. Haber GB, Heaton KW, Murphy D, et al. (1977) Depletion and disruption of dietary fibre. Effects on satiety, plasma-glucose, and serum-insulin. Lancet ii, 679-682.

36. Mattes RD \& Rothacker D (2001) Beverage viscosity is inversely related to postprandial hunger in humans. Physiol Behav 74, 551-557. 